\title{
Spremembe zakona o varstvu okolja - v kateri smeri?
}

\author{
UDK: 504.064 (497.4)

\section{Adrijana Viler Kovačič} \\ Agencija RS za okolje za izvajanje okoljevarstvene zakonodaje \\ adrijana.viler-kovacic@gov.si
}

\section{IZVLEČEK}

Pravico do zdravega življenjskega okolja, ki jo ustava deklarira kot eno izmed temeljnih ustavnih pravic, ureja več zakonov, med katerimi je najpomembnejši Zakon o varstvu okolja. V okviru uresničevanja omenjene ustavne pravice Zakon o varstvu okolja določa obveznosti javne oblasti, kakor tudi dolžnosti onesnaževalcev, da bi tako zagotavljali čim manjše obremenjevanje okolja in trajnostni razvoj. V članku so predstavljena načela tega zakona ter okvir zakonodaje varstva okolja. Podani so tudi razlogi, ki narekujejo zahteve za spremembo tega zakona, nanašajo pa se po eni strani na prenos evropskih direktiv (odgovornost za okoljsko škodo in trgovanje z emisijami), po drugi pa na odpravljanje nekaterih ne preveč posrečenih rešitev pri izvedbi postopka presoje vplivov na okolje in izdaje okoljevarstvenega soglasja, kakor tudi na nekoliko drugačna razporeditev pridobivanja gradbenih in okoljevarstvenih dovoljenj.

Ključne besede: zakonodaja, okoljevarstvo, Slovenija, ustavne pravice, onesnaževanje

\section{Varstvo okolja - ustavna kategorija}

Okoljevarstvena zakonodaja oziroma pravo varstva okolja je namenjeno zagotovitvi takega stanja okolja, da ni ogroženo zdravje in človeka vredno življenje. Gre predvsem za varovanje zraka, voda, tal, rastlinskega in živalskega sveta pred škodljivimi posegi človeka, ustreznega ravnanja z odpadki, za odpravljanje škode ter škodljivih posledic zaradi varovanja človeka. Varstvo okolja ne more pomeniti samo varstva pred onesnaženjem, temveč tudi varstvo prijetnega, dostojanstvenega in kakovostnega življenja.

Slovensko pravo varstva okolja ima svojo izhodišče v Ustavi Republike Slovenije, ki v prvem odstavku 72. člena določa, da ima vsakdo v skladu z zakonom pravico do zdravega življenjskega okolja. Določba je sicer uvrščena $\vee$ tretje poglavje ustave, ki nosi naslov »Gospodarska in socialna razmerja « in ne 
Adrijana Viler Kovačič

Spremembe zakona o varstvu okolja - v kateri smeri?

med temeljne človekove pravice in svoboščine, a ne glede na to je to ustavno varovana pravica, oziroma je uresničljiva že samo na podlagi ustave in je lahko predmet varstva $\vee$ postopku odločanja o ustavni pritožbi ${ }^{\mathbf{1}}$. Pravica do zdravega življenjskega okolja bi posredno lahko tudi sodila med človekove pravice glede na dejstvo, da je za varovanje te pravice izrecno pristojen tudi varuh človekovih pravic.

Ustava v drugem odstavku 72. člena določa tudi, da država skrbi za zdravo življenjsko okolje ter da $v$ ta namen zakon določa pogoje in načine za opravljanje gospodarskih in drugih dejavnosti. S tem je dana državi aktivna vloga $v$ zvezi $z$ varstvom okolja oziroma ohranjanjem naravnega ravnovesja. To svojo nalogo izvršuje prek instrumentov zakonodajne, izvršilno upravne in sodne veje oblasti. Neizvajanje te naloge, torej opustitev normativnega urejanja pogojev in način za opravljanje gospodarskih in drugih dejavnosti, bi bilo neustavno ${ }^{2}$.

Med instrumenti izvršilno upravne veje oblasti sodi sistem nadzora nad izvajanjem dejavnosti, ki lahko povzročajo negativne posledice na okolje. Ta sistem po eni strani pomeni uveljavitev obveznosti pridobitve vrste upravnih aktov (soglasij, dovoljenj, potrdil) pred izvajanjem teh dejavnosti, $\vee$ okviru katerih državna oblast preverja predvidene posege $\vee$ okolje ter zaradi varstva okolja morebiti določa še posebne dodatne pogoje posegov, po drugi pa podreditev sistemu upravnega in inšpekcijskega nadzora tako nad izvrševanjem okoljskih predpisov kakor izdanih upravnih aktov.

\section{Stanje okolja v Sloveniji}

$\checkmark$ drugi polovici 20. stoletja sta dva razvojna procesa, industrializacija in urbanizacija, tako hitro in učinkovito napredovala, da skrb za naravo in varstvo obdelovalnih tal ni bila dovolj učinkovito sito pri posegih $v$ naravo in urejanju človekovega okolja. Po eni strani se Slovenija ponaša z lepoto ter biotsko in pokrajinsko zelo pestro in ohranjeno naravo, po drugi pa so nekatera gosteje naseljena območja prizadeta zaradi onesnaževanja tal, zraka in vodovja ter neurejenega ravnanja z odpadki. To vsekakor vpliva tudi na življenje prebivalcev.

1 sklep Ustavnega sodišča Republike Slovenije Up 41/94

2 odločba Ustavnega sodišča U-I-263/95 
Koncept uravnoteženega gospodarskega, socialnega in okoljskega razvoja se $\vee$ Sloveniji ne uresničuje $\vee$ celoti. Gospodarska razvitost se povečuje ob hkratnem socialnem razvoju, vendar počasnejšem uveljavljanju skrbi za okolje. Tako je gospodarska rast delno dosežena tudi na škodo okolja, na kar vplivajo visoka energetska intenzivnost ter neugodne stopnje rasti emisijsko najbolj intenzivnih industrij in intenzivnega kmetijstva ter drugih sektorskih netrajnostnih politik ${ }^{3}$.

Zakonodaja varstva okolja mora pripomoči $k$ doseganju višje ravni varstva okolja, pri čemer pa se mora zavedati skladnosti s cilji gospodarskih in socialnih razsežnosti trajnostnega razvoja. Varstvo okolja zahteva izvedbo vseh ukrepov za zmanjšanje njegovega obremenjevanja, uravnoteženo gospodarsko proizvodnjo in rabo energije, gospodarstvo pa za svoj razvoj pričakuje učinkovitost upravnih organov, manj birokracije in nižje stroške nadzora nad izvajanjem predpisov.

\section{Zakon o varstvu okolja}

Temeljni predpis, ki ureja področje varstva okolja v Sloveniji, je Zakon o varstvu okolja ( ${ }^{\boldsymbol{4}}$ nadaljevanju ZVO-1). Zakon je bil sicer sprejet v letu 2004, a je bil v letu 2006 spremenjen in dopolnjen z Zakonom o spremembah in dopolnitvah Zakona o varstvu okolja ${ }^{\mathbf{5}}$, izdan je bil tudi v prečiščenem besedilu ${ }^{\mathbf{6}}$. Zakon je posredno doživel spremembe $v$ letu 2007 z Zakonom o prostorskem načrtovanju', po katerem so bili črtani določeni členi, ki so se nanašali na postopek za izdajo okoljevarstvenega soglasja $\vee$ okviru sprejemanja prostorskih aktov. Z uveljavitvijo ZVO-1 je prenehal veljati prejšnji Zakon o varstvu okolja ${ }^{\boldsymbol{s}}$, sprejet leta 1993, ki je že tedaj postavil temelje sodobnega varstva okolja $\vee$ Republiki Sloveniji, saj je poenotil principe varstva okolja tako, da je do tedaj običajni način reševanja vedno večjih okoljskih problemov z uporabo tehničnih rešitev omejevanja onesnaževanja prevedel $\vee$ kontekst zagotavljanja trajnostnega razvoja.

3 Resolucija o Nacionalnem programu varstva okolja 2005-2012 /ReNPVO/ (Ur.l. RS, št. 2/2006)

4 ZVO-1, Uradni list RS, št. 41/2004

5 ZVO-1A, Uradni list RS, št. 20/2006

6 ZVO-1-UPB1, Uradni list RS, št. 39/2006

7 ZPNačrt, Uradni list RS, 33/2007

8 ZVO, Uradni list RS, št. 32/1993, 1/1996, 56/1999 - ZON, 22/2000 - ZJS, 67/2002 - ZV-1 


\section{Adrijana Viler Kovačič}

\section{Spremembe zakona o varstvu okolja - v kateri smeri?}

ZVO-1 ureja varstvo okolja pred obremenjevanjem kot temeljnim pogojem za trajnostni razvoj in $\vee$ tem okviru določa temeljna načela in ukrepe varstva okolja, načine in pogoje spremljanja stanja okolja in informacije o okolju, ekonomske in finančne instrumente, javne službe in druga z varstvom okolja povezana vprašanja. Med najpomembnejšimi načeli velja poudariti:

- načelo preventive, po katerem je uvajanje novih tehnologij, proizvodnih postopkov in izdelkov dopustno le, če ob upoštevanju stanja znanosti in tehnike ter možnih varstvenih ukrepov ni pričakovati nepredvidljivih škodljivih učinkov na okolje ali zdravje ljudi;

- načelo previdnosti, po katerem morajo biti mejne vrednosti emisije, standardi kakovosti okolja, pravila ravnanja in drugi ukrepi varstva okolja zasnovani, vsak poseg v okolje pa načrtovan in izveden tako, da povzroči čim manjše obremenjevanje okolja. Za uresničevanje teh določb se uporabljajo najboljše razpoložljive tehnike, dostopne na trgu;

- načelo dopustnosti posegov $v$ okolje, po katerem je poseg $v$ okolje dopusten le, če ne povzroča čezmerne obremenitve;

- načelo plačila za obremenjevanje, po katerem povzročitelj obremenitve krije vse stroške predpisanih ukrepov za preprečevanje in zmanjševanje onesnaževanja ter tveganja za okolje, rabo okolja ter odpravo posledic obremenjevanja okolja.

Zakon je posegel tudi na področje graditve objektov, saj je zahteval, da mora investitor pred izvedbo posega $v$ okolje oziroma gradnjo določenih objektov, ki imajo vpliv na okolje, pridobiti več upravnih aktov (okoljevarstveno soglasje, okoljevarstvena dovoljenja). Te zahteve so tako pomembne tudi za organe, ki izdajajo gradbena dovoljenja za zagotavljanje njihove zakonite in pravilne izdaje, saj je pridobitev okoljevarstvenih aktov marsikdaj tudi predpogoj za izdajo gradbenega dovoljenja.

Zakonodajo varstva okolja tvorijo tudi podzakonski akti (uredbe, pravilniki), ki so bili sprejeti na podlagi ZVO-1 (teh je bilo do konca septembra 2007 že več kot 150), pa tudi tisti, ki so bili sprejeti na podlagi Zakona o varstvu okolja iz leta 1993 in so po izrecni določbi ZVO-1 še vedno veljavni. Gre za podzakonske akte na področju varstva kakovosti zraka, voda in tal, varstva pred hrupom in sevanji, ki velikokrat tudi določajo tehnične pogoje in okoljevarstvene zahteve za gradnjo objektov kot virov onesnaževanja okolja. 


\section{Spremembe Zakona o varstvu okolja}

Po štirih letih od uveljavitve novega Zakona o varstvu okolja je tako napočil čas za ugotovitev, ali je ta izpolnil pričakovanja oziroma ali je še $v$ celoti ustrezen. Vse več je namigovanj, da bi bilo treba uveljaviti nekatere spremembe, po eni strani zaradi zahtev evropske zakonodaje, po drugi pa zaradi uveljavitve nekaterih fleksibilnejših institutov varovanja okolja. Zahtevo po spremembi oziroma dopolnitvi pa narekujeta tudi sodna in upravna praksa zaradi različnega tolmačenja nekaterih zakonskih določb.

Ne gre pozabiti tudi na to, da se je Republika Slovenija zavezala k celovitemu izvajanju Lizbonske strategije oziroma izvajanju njenih ukrepov na nacionalni ravni, $\vee$ gospodarskih, socialnih in okoljskih razsežnostih. $V$ sklopu politike boljših predpisov in s ciljem doseganja višje konkurenčnosti se mora tako spoprijeti s pripravo boljših predpisov, z zmanjšanjem administrativnih bremen vključno z merjenjem administrativnih stroškov ter s pripravo ocene učinkov predpisov na državljane in gospodarstvo ${ }^{9}$. Gre torej za poenostavitev zakonodaje ter za odpravo administrativnih ovir kot procesa zmanjševanja, odprave ali preprečitve administrativnih bremen, ki implicitno zajema tudi proces poenostavitve upravnih postopkov. Pri vsem tem se pa mora tudi zavedati, da se vse spremembe ne smejo zgoditi na škodo varstva okolja oziroma varstva človekovih pravic.

\subsection{Prilagoditev direktivi 2004/35/ES glede odgovornosti za okoljsko škodo}

V naš pravni sistem še nimamo vgrajene Direktive 2004/35/ES10, ki so jo morale države članice prenesti $v$ nacionalne pravne rede do 30. aprila 2007. Ta direktiva je bila sprejeta zaradi spoznanja, da je na območju skupnosti že sedaj veliko onesnaženih območij, ki povzročajo večje tveganje za okolje, v zadnjem času pa se je dramatično povečala tudi izguba biotske raznovrstnosti. Direktiva izhaja iz načela, da onesnaževalec plača vse stroške, ki so potrebni za preprečevanje in sanacijo okoljske škode. Direktiva določa, da mora povzročitelj nevarnosti za nastanek okoljske škode sam nemudoma izvesti preventivne ukrepe, s katerimi prepreči nastanek okoljske škode. V primeru nastanka okoljske škode mora povzročitelj izvesti vse potrebne ukrepe za ustavitev in zmanjšanje

9 Več o tem http://ec.europa.eu/growthandjobs/index.htm 10 Direktiva 2004/35/ES Evropskega parlamenta in Sveta z dne 21. aprila 2004 o okoljski odgovornosti $v$ zvezi s preprečevanjem in sanacijo okoljske škode 
Adrijana Viler Kovačič

Spremembe zakona o varstvu okolja - v kateri smeri?

posledic, o nastanku škode nemudoma obvestiti pristojni organ, ki ga določi država članica, in izvesti sanacijske ukrepe za sanacijo okoljske škode. Lastniki zemljišč in druge osebe, ki bi jim bil zaradi nastale škode prizadet pravno varovan interes, med katere se uvrščajo tudi nevladne organizacije, imajo pravico aktivne pobude za naprtitev preventivnih ali sanacijskih ukrepov, pri čemer pa je državam članicam prepuščeno, ali bodo to pravico podelile le $v$ primeru nastanka okoljske škode ali pa tudi v primeru nevarnosti za njen nastanek.

Direktiva vsebuje tudi zahtevo, da naj države članice sprejmejo ukrepe, s katerimi bodo spodbujale razvoj finančnih instrumentov, ki naj bi jih povzročitelji uporabljali za finančno pokritje svojih obveznosti za izvedbo preventivnih ali sanacijskih ukrepov, pri čemer pa ne določa vrste oz. načine izvedbe tega kritja. Prav tako nalaga državam članicam, da sprejmejo takšno ureditev, ki bo državi omogočala povrnitev stroškov subsidiarnega ukrepanja in sicer z jamstvom na premoženju povzročitelja ali drugimi ustreznimi garancijami.

Naj poudarimo, da direktiva ne posega $v$ odgovornost za škodo, ki je urejena $v$ civilnem pravu, $v$ Republiki Sloveniji torej $v$ obligacijskem zakoniku, in $v$ odgovornost za povzročitev škode, ki je urejena s posameznimi mednarodnimi pogodbami.

\subsection{Trgovanje z emisijskimi kuponi"}

Po uveljavitvi ZVO-1 in njegovih sprememb se je $v$ letu 2005 praktično začelo prvo poskusno obdobje trgovanja z emisijskimi kuponi, kot popolnoma novem ekonomskem institutu varstva okolja, s katerim večina držav članic Evropske unije (razen Velike Britanije in Danske, ki sta imeli že prej uveljavljen nekakšen sistem trgovanja z določenimi emisijskimi pravicami), ni imela praktično nobenih izkušenj. Praktične izkušnje $v$ prvem obdobju, ki se je začelo leta 2005 in se bo zaključilo konec leta 2007, so pokazale na nekatere pomanjkljivosti, ki zahtevajo bolj natančno ureditev določenih vprašanj oziroma prilagoditev določenih rešitev.

Da bo Republika Slovenija lahko omogočila izvajanje skupnih naložb in da bodo slovenska podjetja lahko pridobila enote na podlagi skupnih naložb, je treba urediti ves postopek preverjanja in odobritve skupnih naložb ter podelitev ustreznih kjotskih enot. Administrativno kompleksen in zahteven postopek

11 Trgovanje z emisijami toplogrednih plinov ureja Direktiva 2004/101/ES Evropskega parlamenta in Sveta z dne 27. oktobra 2004 o dopolnitvi Direktive 2003/87/ES o vzpostavitvi sheme za trgovanje s pravicami za izpuščanje toplogrednih plinov v Skupnosti, upoštevajoč projektne mehanizme Kjotskega protokola (UL L št. 338 z dne 13. 11. 2004, stran 18) 
odobritve projektne dejavnosti od pristojnega organa Republike Slovenije vključuje pregled in ovrednotenje projektnega dokumenta z vidika njegove ustreznosti in skladnosti s Sklepi 7. konference pogodbenic Okvirne konvencije ZN o spremembi podnebja iz Marakeša (Marakeški sklepi). Za sodelovanje v skupnih naložbah mora država pogodbenica Kjotskega protokola imenovati pristojno koordinacijsko telo in o tem obvestiti sekretariat Okvirne konvencije ZN o spremembah podnebja; to je Designated Focal Point za sodelovanje pri skupnem izvajanju in Designated National Authority za sodelovanje pri mehanizmu čistega razvoja. Na podlagi Marakeškega sklepa št. 16 mora država pogodbenica predpisati tudi postopek za odobritev projektov skupnega izvajanja, njihovega spremljanja in preverjanja ter svoja navodila, skupaj z upoštevanjem pripomb zainteresirane javnosti, posredovati sekretariatu Okvirne konvencije. Nadalje je treba opredeliti, na kakšen način organ, pristojen za odobritev skupnih naložb, zagotovi, da je pri opredelitvi izhodiščnega stanja skupnih naložb pri projektih, izvedenih $\vee$ drugih državah EU, v celoti upoštevana zakonodaja EU, oziroma na kakšen način je to mogoče preveriti z neodvisnim preverjanjem. Prav tako je treba na podlagi strokovnih podlag sprejeti odločitev in jo tudi zakonsko urediti, ali bo Republika Slovenija na svojem ozemlju sploh dovolila projekte skupnega izvajanja in če bo, določiti postopek odobritve ustrezne projektne dejavnosti.

\subsection{Presoja vplivov na okolje in okoljevarstveno soglasje}

Postopek izvedbe presoje vplivov na okolje (PVO) in izdaje okoljevarstvenega soglasja je urejal že prvi Zakon o varstvu okolja, sprejet v letu $1993^{\mathbf{1 2}}$, ko je $\vee$ naš pravni sistem prenesel zahteve Direktive 85/337/EGS ${ }^{\mathbf{1 3}}$. Postopek PVO se je tedaj izvedel $\vee$ postopku izdaje okoljevarstvenega soglasja kot akcesornega akta pri izdaji gradbenega dovoljenja. Zaradi kasneje sprejetih direktiv (Direktiva 97/11/ES ${ }^{\mathbf{1 4}}$ in Direktiva 2003/35/EGS ${ }^{\mathbf{1 5}}$ ), ki sta uvedli še posebne

12 Uradni list RS, št. 32/93

13 Direktiva Sveta 85/337/EGS z dne 27. junija 1985 o oceni vplivov določenih javnih in zasebnih projektov na okolje

14 Direktiva Sveta 97/11/EGS z dne 3. marca 1997 o dopolnitvi Direktive 85/337/EGS z dne 27. junija 1985 o oceni vplivov določenih javnih in zasebnih projektov na okolje

15 Direktiva 2003/35/EGS Evropskega parlamenta in Sveta z dne 26. maja 2003 o zagotavljanju udeležbe javnosti pri sprejemanju določenih planov in programov, ki se nanašajo na okolje, in dopolnitvah, ki se nanašajo na udeležbo javnosti in dostop do pravice. 


\section{Adrijana Viler Kovačič}

\section{Spremembe zakona o varstvu okolja - v kateri smeri?}

zahteve glede sodelovanja javnosti, kakor tudi izhajajoč iz Aarhuške konvencije ${ }^{\mathbf{1 6}}$, taka rešitev ni bila več ustrezna $v$ celoti. Taka ureditev ni bila več ustrezna tudi zaradi sprejema novega Zakona o graditvi objektov koncem leta 2002, ki je zožil nabor primerov, ko je gradbeno dovoljenje potrebno pridobiti, kar je povzročilo, da se postopek presoje vplivov na okolje za določene posege ni mogel izvesti (npr. za izkoriščanje gramoza v vodotokih).

Kot podlago za izvedbo PVO obstoječi zakon zahteva poleg poročila o vplivih na okolje tudi revizijo tega poročila. Poročilo lahko izdeluje kdorkoli, medtem ko revizijo lahko izdelujejo le okoljski izvedenci, imenovani s posebno odločbo ministra za okolje. Ta način naj bi zagotavljal pretehtano in dobro proučeno preverjanje ustreznosti posega z vidika njegovega vliva na okolje, po drugi strani pa olajšal upravnemu organu (Agenciji RS za okolje) postopek izdaje okoljevarstvenega soglasja.

Štiriletne izkušnje pa so pokazale, da revizije ne pomenijo dviga kakovosti izdelave poročil o vplivih na okolje, kot je bil namen uvedbe revizij, saj je treba v marsikaterih primerih kljub pozitivnemu revizijskemu mnenju dopolniti poročilo o vplivih na okolje, ker je ta pomanjkljiv oziroma neustrezen. Zato mogoče ne bi bilo narobe, če bi se revizije ukinile, pri čemer pa bi bilo treba nujno ponovno zahtevati določeno strokovno usposobljenost za izdelovalce poročil o vplivih na okolje. Izdelovalci poročil bi lahko bili le tisti, ki jih imenuje oziroma pooblasti Ministrstvo za okolje in prostor. Naj za primerjavo navedemo sistem izdelave projektov pri pridobivanju gradbenih dovoljenj, ko zakonodaja ne omogoča, da bi lahko projekt izdeloval kdorkoli, pač pa le projektant, ki je za vse načrte, ki sestavljajo projekt, imenoval odgovorne projektante, ki izpolnjujejo določene pogoje ${ }^{17}$. Več pozornosti bi pa morali posvetiti tudi sankcijam, ki bi prizadele izdelovalce neustreznih poročil, predvsem z vidika varovanja interesov investitorja in kakovosti tako pomembnega dokumenta.

V postopku PVO ter izdaje okoljevarstvenega soglasja je treba javnosti zagotoviti vpogled $v$ vlogo, $v$ poročilo o vplivih na okolje reviziji in na osnutek odločitve, to se pa izvede $v$ okviru javne razgrnitve omenjenih dokumentov. Ta razgrnitev je strošek, ki bremeni stranko. $V$ praksi se je že zgodilo, da je bila izdana negativna odločba brez izvedbe javne razgrnitve, a ne zaradi tega, ker bi bil vpliv na okolje preveč škodljiv, pač pa zaradi dejstva, da obstoječi predpisi predvidenega posega niso dopuščali. Odločujoči organ je namreč ocenil, da

16 Zakon o ratifikaciji konvencije o dostopu do informacij, udeležbi javnosti pri odločanju in dostopu do pravnega varstva v okoljskih zadevah (MKDIOZ) - Uradni list RS, št. 62/2004 17 45. člen Zakona o graditvi objektov (ZGO-1-UPB1, Ur.I. RS, št. 102/2004, 14/2005 - popr.) 
skladno z načelom ekonomičnosti ni primerno stranki po nepotrebnem zadati dodatne in nepotrebne stroške javne razgrnitve. Vendar pa je $\vee$ pritožbenem postopku organ druge stopnje odpravil to odločbo z obrazložitvijo, da se postopek ni odvijal do konca točno tako, kot ga predvideva ZVO-1. Zagotovo bi se to različno pravno gledanje oziroma anomalija odpravila, če bi ZVO-1 določil, da javne razgrnitve ni treba izvesti, če obstoječi predpisi že sami po sebi prepovedujejo ali pa ne omogočajo izvedbe posega tako, kot ga je investitor nameraval izvesti.

$\checkmark$ postopku izdaje okoljevarstvenega soglasja lahko kot stranski udeleženci sodeluje velik krog oseb, ki imajo lastnost stranke $\vee$ postopku (osebe, ki na vplivnem območju stalno prebivajo ter lastniki in posestniki zemljišč $v$ vplivnem območju, nevladne organizacije, ki imajo poseben status delovanja $v$ javnem interesu). Izhodišče ZVO-1 o tem, da mora organ sam poiskati te osebe, je morebiti preveč restriktivno, saj to terja preverjanje vsemogočih evidenc. Velik problem je tudi identifikacija posestnikov nepremičnin, saj take evidence naš pravni sistem sploh ne predvideva. Poleg tega se lahko zgodi, da stranski udeleženec zahteva vstop $v$ postopek tik pred izdajo okoljevarstvenega soglasja, kar pomeni avtomatično podaljšanje že tako dolgega postopka. Sodelovanje javnosti bi se lahko skladno z direktivo uredilo tako, da bi se za stranskega udeleženca zahtevalo več lastne aktivnosti za priznanje tega statusa. Zato bi bilo primerno določiti, da je lahko stranski udeleženec le oseba, ki aktivno izkaže namero sodelovati $\vee$ postopku in sicer če sama da vlogo za priznanje statusa stranke $\vee$ postopku in je $\vee$ času javne razgrnitve (in ne po njenem izteku) podala svoje mnenje na dokumentacijo.

Izredno velik problem in tudi medijskega prahu je nedavno povzdignilo vprašanje, ali gre društvu, ki sicer ni pridobilo statusa nevladne organizacije, ki na področju varstva okolja deluje $v$ javnem interesu po 153. členu ZVO-1, pač pa status društva po 138 . členu Zakona o ohranjanju narave ${ }^{\mathbf{1 8}}$, status stranke $\vee$ postopku izdaje okoljevarstvenega soglasja za poseg na območju, varovanem po ZON-UPB2. Mnenja upravnih organov, sodišč ter pravnih strokovnjakov so si bila $v$ konkretnem primeru ${ }^{19}$ diametralno nasprotna tudi v okviru istega nivoja obravnave, saj je bilo vse odvisno od konkretne osebe, ki je tolmačila zakonodajo. Takemu stanju, ki je povzročilo investitorju tudi velike stroške, je botrovalo nedodelano določilo 64.člena ZVO-1, ki napotuje na 153. člen, zaradi česar

18 Zakon o ohranjanju narave (ZON-UPB2, Uradni list RS, št. 96/2004)

19 gre za primer izdaje okoljevarstvenega soglasja za gradnjo vetrne elektrarne na Volovji rebri v občini llirska Bistrica 
Adrijana Viler Kovačič

Spremembe zakona o varstvu okolja - v kateri smeri?

ga je treba spremeniti in tako bolje ter natančneje opredeliti, da se bodo tako preprečile različne interpretacije istega zakonskega besedila.

Namesto ničnosti dovoljenja za poseg v prostor, kot morebiti preveč hudo sankcijo za primer, če okoljevarstveno soglasje ni bilo pridobljeno, ki ga predvideva obstoječi ZVO-1, bi lahko vpeljali možnost, da se za pridobitev gradbenega dovoljenja zahteva pravnomočnost tega soglasja ter da se za primer upravnega spora sodišču določi rok za odločanje.

\subsection{Skupno vodenje presoje vplivov na okolje (PVO) in celovite presoje vplivov na okolje (CPVO)}

Presoje vplivov na okolje (PVO) ne smemo zamenjevati s celovito presojo vplivov na okolje (CPVO), ki jo je prav tako vpeljal ZVO-1 v letu 2004 zaradi zahtev Direktive 2001/42/ES ${ }^{20}$. CPVO je postopek, ki se izvede pred sprejemanjem prostorskega ali drugega plana, če obsega posege, za katere je presoja vplivov na okolja obvezna ali pa če je zanje zahtevana presoja sprejemljivosti po Zakonu o ohranjanju narave (to je, ko gre za posege na zavarovanih območjih in Natura območjih ali pa bi nanje imeli poseben vpliv). To je proces uvajanja okoljskih vidikov pri načrtovanju in optimizacijski postopek izbiranja okoljsko primernih variant z vključevanjem javnosti. CPVO je tudi upravni postopek, ki ga vodi Ministrstvo za okolje in prostor tako, da presoja verjetne pomembne vplive plana, preverja kakovost okoljskega poročila in odloča o sprejemljivosti posega (s sklepom o potrditvi plana oziroma odločbo o zavrnitvi izdaje potrdila o potrditvi plana).

Poudariti pa je treba, da CPVO ne izključuje presoje vplivov na okolje, če je ta obvezna, kar pomeni, da je treba kljub izvedeni CPVO izvesti tudi presojo vplivov na okolje in tudi tako pridobiti okoljevarstveno soglasje. Načeloma naj se C postopka PVO in PVO ne bi prekrivala, saj se CPVO nanaša na načrte in programe, PVO pa na konkretne posege. Kadar pa se z načrtom ali programom pripravlja tudi eden ali več posegov, ki zapadejo pod obveznost CPVO, lahko pride do vsebinskega prekrivanja in podvajanja. $\vee$ slovenski praksi zaradi načina transpozicije obeh direktiv $\vee$ pravni red preko ZVO-1 prihaja ponekod do takšnega vsebinskega podvajanja, okoljsko poročilo, kot podlaga za CPVO, je tedaj vsebinsko zelo blizu poročilu o vplivih na okolje, kot podlage za PVO. Postopka se skladno z zakonodajo sicer vodita ločeno, najprej CPVO in nato

20 Direktiva 2001/42/ES Evropskega parlamenta in Sveta o presoji nekaterih načrtov in programov na okolje 
PVO. Posebna določila o sodelovanju javnosti in strankah $\vee$ postopku so v ZVO1 vključena $\vee 58$. in 64. členu, ki govorita o postopku PVO in ne o C postopku PVO.

Da bi poenostavili postopke ter se izognili vsebinskemu podvajanju, bi lahko $\checkmark$ spremembe ZVO-1 vključili takšne rešitve, da bi se za določene projekte, za katere je potrebno izvesti CPVO, lahko PVO izpeljal vzporedno ali skupaj. Na ta način bi preprečili možnost podvajanja, omogočili uporabo relevantnih ugotovitev iz postopka CPVO v postopku PVO itd. Tudi $\vee$ 11. členu Direktive 2001/42/ES je navedeno, da države članice lahko za načrte in programe, pri katerih je obveznost izvesti PVO predpisana hkrati s to direktivo in tudi po drugi zakonodaji Skupnosti, poskrbijo za usklajene ali skupne postopke, ki izpolnjujejo zahteve ustrezne zakonodaje Skupnosti, zato da med drugimi preprečijo podvajanje presoje.

\subsection{Izdajanje okoljevarstvenih dovoljenj}

Okoljevarstveno dovoljenje je popolnoma nov upravni akt, ki ga je $v$ letu 2004 uvedel ZVO-1. Vezano je na zahtevo, da mora biti vsak poseg $\vee$ okolje načrtovan in izveden tako, da povzroči čim manjše obremenjevanje okolja (načelo preventive). Povzročitelj onesnaževanja mora tako po izrecni zakonski dikciji za napravo, v kateri poteka dejavnost, ki lahko onesnažuje okolje z emisijami, imeti okoljevarstveno dovoljenje, kar pa ne velja $v$ vseh primerih onesnaževanja, pač pa tedaj, ko naprava izpolnjuje $v$ zakonu ali podzakonskem aktu določene pogoje. Tako je okoljevarstveno dovoljenje treba pridobiti za obratovanje

- naprav, ki lahko povzročajo onesnaževanje večjega obsega (naprave iz 68. člena zakona),

- drugih naprav, ki niso naprave iz prejšnje alinee (naprave iz 82. člena zakona), če se $v$ njih:

- izvaja dejavnost, ki povzroča emisije $v$ zrak, vode ali tla, za katere so predpisane mejne vrednosti,

- izvaja dejavnost, za katero je predpisana obveznost pridobitve okoljevarstvenega dovoljenja po drugih predpisih,

- predelujejo oziroma odstranjujejo odpadki;

- obratov, ki pomenijo večja tveganja za okolje (obrati iz 86. člena zakona).

Vsa dovoljenja izdaja ARSO. Razlika med njimi je zlasti v obsegu zahtev, ki morajo biti izpolnjene za pridobitev dovoljenja, $v$ roku za izdajo dovoljenja in $\vee$ 


\section{Adrijana Viler Kovačič}

\section{Spremembe zakona o varstvu okolja - v kateri smeri?}

udeležbi javnosti. Vsem dovoljenjem pa je skupno to, da se morajo pridobiti pred pričetkom obratovanja naprave oziroma obrata, pri čemer pa je tudi določen rok za pridobitev tega dovoljenja za obstoječe naprave (najkasneje do 31. oktobra 2007 oziroma za nekatere izjeme do 31. oktobra 2011). Če pa obratovanje ali večja sprememba $\vee$ obratovanju zahteva gradnjo, mora upravljavec okoljevarstveno dovoljenje pridobiti pred začetkom gradnje.

Zahteve po izdajanju teh dovoljenj slonijo predvsem na evropskih direktivah. Direktive zahtevajo od držav članic, da sprejmejo potrebne ukrepe za zagotovitev, da nobena naprava, ki sodi pod specifično direktivo, ne obratuje brez dovoljenja; nekatere direktive so določile tudi datum prilagoditve obstoječim napravam. Izdaje posebnega dovoljenja pa ne zahteva Direktiva Sveta 96/82/ES ${ }^{21}$, ki je podlaga za uvedbo ureditve obvladovanja nevarnosti večjih nesreč, $v$ katere so vključene nevarne snovi in izdaje okoljevarstvenega dovoljenja po 86. členu ZVO-1. Ta direktiva namreč $\vee$ smislu upravnega nadzora zahteva le prijavo oziroma priglasitev naprave ter potrditev varnostnega poročila pred gradnjo oziroma obratovanjem. Direktiva torej ne zahteva izrecnega okoljevarstvenega dovoljenja; izrecno pa uvaja obveznost odreditve prepovedi obratovanja, če upravljavec naprave ni posredoval priglasitve oziroma, če so ukrepi za preprečevanje in ublažitev posledic večjih nesreč zelo pomanjkljivi ${ }^{\mathbf{2 2}}$. Zahteva slovenske zakonodaje o tem, da morajo upravljavci obratov, ki pomenijo večje tveganje za okolje, pridobiti pred gradnjo okoljevarstveno dovoljenje, ni v nasprotju z določili direktive, sodi pa $v$ okvir ukrepov, ki jih mora država sprejeti za izvajanje direktive. Vendar pa tu nastopi vprašanje, ali ni taka zahteva morebiti odveč, posebno še zato, ker doslej ni bilo izdanega nobenega tovrstnega okoljevarstvenega dovoljenja, niti ni nobene perspektive, da bi bilo katero za obstoječe obrate sploh izdano do 31.10.2007, kakor je to zahteva iz Uredbe o preprečevanju večjih nesreč in zmanjševanju njihovih posledic ${ }^{\mathbf{2 3}}$. Zakonodajalec se je odločil za ta način urejanja predvsem zaradi velike okoljevarstvene nediscipline in relativno premalo uspešne okoljske inšpekcije. Morebiti pa ne bi bilo narobe ponovno preveriti, ali je zahteva po izdaji okoljevarstvenega dovoljenja za te primere še potrebna oziroma ali ne bi bilo možno zadostiti direktivi tudi na kakšen drug način, na primer z izboljšanjem sistema upravnega in inšpekcijskega nadzora.

21 Direktiva Sveta 96/82/ES z dne 9. decembra 1996 o obvladovanju nevarnosti večjih nesreč, $v$ katere so vključene nevarne snovi

22 17. člen direktive

23 Uradni list RS, št. 88/05 
Izdajanje okoljevarstvenih dovoljenj po 82. členu ZVO-1 podrobneje ureja cela vrsta podzakonskih aktov, tako na področju varstva voda, varstva zraka, varstva pred hrupom in ravnanja z odpadki. Bolj ali manj gre za uvedbo evropskih direktiv na tem področju, ki zahtevajo izdajo predhodnega dovoljenja bodisi pred izpustom $\vee$ okolje ali pa za izvajanje dejavnosti ravnanja z odpadki. Po sedanjem slovenskem sistemu se okoljevarstvena dovoljenja izdajajo pred gradnjo oziroma pred izdajo gradbenega dovoljenja. Problem nastopi zaradi tega, ker $\vee$ tem času ni mogoče tako natančno določiti pogojev obratovanja, tako da se $\vee$ teh dovoljenjih bolj ali manj prepišejo zahteve iz posameznih uredb. čestokrat se pa tudi zgodi, da stranka šele po pridobitvi gradbenega dovoljenja oziroma $v$ času gradnje dokončno predvidi svoj tehnološki postopek, oziroma vrsto odpadkov, ki jih bo predelovala ali odstranjevala.

Veliko primerneje in bolj racionalno bi bilo, če bi se pridobivanje okoljevarstvenega dovoljenja po 82. členu ZVO-1 zahtevalo šele pred izdajo uporabnega dovoljenja, saj bi bili tedaj veliko bolj jasni in nedvoumni pogoji obratovanja. S tem bi to dovoljenje postalo "obratovalno dovoljenje», kot ga je nekoč zakonodaja tudi poznala. Okoljevarstvene zahteve pred gradbenim dovoljenjem bi bile lahko ustrezno zavarovane v okviru PVO oziroma okoljevarstvenega soglasja, če bi bila presoja obvezna. Če pa PVO ne bi bila obvezna, bi bilo treba predvideti izdelavo mnogo cenejše strokovne ocene vpliva posega na okolje, kot sestavnim delom vloge za pridobitev gradbenega dovoljenja. S tem bi se zagotovo skrajšal postopek izdaje gradbenega dovoljenja. Naj poudarimo, da je sistem izdelave strokovnih ocen deloval do uveljavitve ZVO-1 leta 2004 in je bil tako $v$ javnosti kakor pri ekspertih dobro sprejet.

\section{Zaključek}

Če hočemo doseči visoko raven stanja okolja, uresničevanje ustavne pravice do zdravega življenjskega okolja ter slediti zahtevam evropskih direktiv, je treba nujno sprejeti takšno okoljevarstveno zakonodajo, ki bo lahko dosegla ta cilj. Za dosego ciljev pa je lahko več poti in več načinov. Zahteve okoljevarstvene zakonodaje so večkrat $v$ nasprotju $z$ interesi gospodarstva, ki zahteva čim višje dobičke. Vlaganje $v$ ekologijo je za gospodarstvo strošek. Zaradi tega je treba to zakonodajo toliko dograditi, da bodo uvedena taka sredstva za dosego ciljev varstva okolja, ki so povezana s čim manjšimi stroški tako za onesnaževalce, kakor za državo in posledično temu tudi davkoplačevalce. Jasna in pregledna zakonodaja je prvi izmed aksiomov, h kateremu bi morali stremeti. Zakon ne bi 


\section{Adrijana Viler Kovačič}

\section{Spremembe zakona o varstvu okolja - v kateri smeri?}

smel dopuščati tako različnih tolmačenj glede pravic strank $v$ postopek, kot se dogaja zdaj. Zagotovo obstajajo še katere druge rešitve, ki lahko pripeljejo do cilja na drug način, kot je obstoječi. Odprava revizorjev pri presoji vplivov na okolje, ki niso doprinesli h kakovosti poročil o vplivih na okolje, pač pa le strošek za investitorja, je nujna. Pri tem pa je se je treba tudi zavedati, da jih je treba nadomestiti z drugim enostavnejšim in učinkovitejšim sredstvom, ne pa enostavno črtati, saj bi tak radikalen poseg povzročil nezadostna in nepopolna poročila o vplivih na okolje in dolgotrajnejše postopke izdaje okoljevarstvenih soglasij, kar pomeni več stroškov za investitorja in tudi več za državo. Prav tako je umestno razmišljanje o drugačni umestitvi okoljevarstvenih dovoljenj po 82. členu Zakona o varstvu okolja v sam postopek gradnje; če bi se ta izdajala pred uporabnim in ne pred gradbenim dovoljenjem, bi bilo doseženo dvoje: investitor bi začel hitreje graditi, upravni organ bi pa tudi lažje in z veliko bolj zanesljivimi podatki izdal okoljevarstveno dovoljenje. Varstvo okolja pa pri tem ne bi bilo v ničemer oškodovano.

Torej - spremembe Zakona o varstvu okolja so na pohodu, a v kateri smeri?

Mag. Adrijana Viler Kovačič, svetovalka generalnega direktorja Agencije RS za okolje za izvajanje okoljevarstvene zakonodaje, se kot diplomirana pravnica profesionalno že dlje časa ukvarja s problematiko varstva okolja, ohranjanja narave ter upravljanje z vodami, večkrat predava na fakulteti ter na več seminarjih in posvetih, ki jih med drugim organizira tudi Ministrstvo za javno upravo oziroma Upravna akademija. V okviru svoje publicistične aktivnosti je objavila vrsto člankov in prispevkov ter dva priročnika (Varstvo okolja in upravni postopki, Ravnanje z odpadki), z delom Koncesije $v$ Sloveniji pa je $v$ letu 2002 zaključila tudi podiplomski magistrski študij na Fakulteti za družbene vede. 


\section{Literatura in viri}

- Report from the Commission to the European Paliament and the Council on the Application and Effecivness of the EIA Direcive (Directive 85/337/EEC as amended by Directive 97/11/EC) - (http://ec.europa.eu/environment/eia/pdf/report_en.pdf).

- Environmental Resorces Management, Edinbourg: Guidance on EIA, Screening, June 2001 (http://ec.europa.eu/environment/eia/eia-guidelines/g-screening-fulltext.pdf).

- Environmental Resorces Management, Edinbourg: Guidance on EIA, Scoping, June 2001 (http://ec.europa.eu/environment/eia/eia-guidelines/g-scoping-fulltext.pdf).

- $\quad$ Presoja vplivov na okolje (http://www.arso.gov.si/varstvo).

- Lisbon Strategy (http://europa.eu/scadplus/glossary/lisbon_strategy_en.htm).

- Environmental Assessment (http://ec.europa.eu/environment/eia/home.htm).

- Environmental impact assessment: A guide to procedures (amended reprint 2001) (http://www.communities.gov.uk/publications/planningandbuilding/environmentali mpactassessment).

- The European IPPC Bureau (http://eippcb.jrc.es/).

- Lawrence P., D. (2003): Environmental Impact Assessment. 2003 John Wiley \& Sons, Inc.

- Kovač, P., Gruden, B. (2006): Interesi pri izdaji gradbenega dovoljenja na lokalni ravni. Pravna praksa, št. 38, letnik.

- $\quad$ Klun, M., Petkovšek, L. (2007): Analiza administrativnih bremen okoljskih predpisov v Sloveniji. Uprava, letnik V, 2/2007, Fakulteta za upravo, Ljubljana.

- Ustava Republike Slovenije.

- Zakon o varstvu okolja ZVO-1-UPB1, Uradni list RS, št. 39/06, 49/06-ZMetD, 66/06OdIUS in 33/07-ZPNačrt.

- Resolucija o Nacionalnem programu varstva okolja 2005-2012 /ReNPVO/ (Ur.I. RS, št. 2/2006).

- Zakon o splošnem upravnem postopku (ZUP - UPB2, Uradni list RS, št. 24/2006, 105/06-ZUS-1, 126/2007).

- Zakon o graditvi objektov (ZGO-1-UPB1, Uradni list RS, št. 102/2004, 14/2005 popr., 92/05-ZJC-B, 111/05 - odločba US, 93/05 - ZVMS in 126/2007).

- Zakon o prostorskem načrtovanju (ZPNačrt, Uradni list RS, 33/2007).

- Zakon o ratifikaciji konvencije o dostopu do informacij, udeležbi javnosti pri odločanju in dostopu do pravnega varstva v okoljskih zadevah (MKDIOZ) - Uradni list RS, št. 62/2004. 


\section{Adrijana Viler Kovačič}

\section{Spremembe zakona o varstvu okolja - v kateri smeri?}

- $\quad$ Direktiva Sveta 85/337/EGS z dne 27. junija 1985 o oceni vplivov določenih javnih in zasebnih projektov na okolje.

- Direktiva Sveta 96/82/ES z dne 9. decembra 1996 o obvladovanju nevarnosti večjih nesreč, $v$ katere so vključene nevarne snovi.

- $\quad$ Direktiva Sveta 97/11/EGS z dne 3. marca 1997 o dopolnitvi Direktive 85/337/EGS z dne 27. junija 1985 o oceni vplivov določenih javnih in zasebnih projektov na okolje.

- Direktiva 2003/35/ES Evropskega parlamenta in Sveta z dne 26. maja 2003 o sodelovanju javnosti pri sestavi nekaterih načrtov in programov v zvezi z okoljem in o spremembi direktiv Sveta 85/337/EGS in 96/61/ES glede sodelovanja javnosti in dostopa do sodišč

- Direktiva 2003/35/EGS Evropskega parlamenta in Sveta z dne 26. maja 2003 o zagotavljanju udeležbe javnosti pri sprejemanju določenih planov in programov, ki se nanašajo na okolje, in dopolnitvah, ki se nanašajo na udeležbo javnosti in dostop do pravice.

- Direktiva 2001/42/ES Evropskega parlamenta in Sveta o presoji nekaterih načrtov in programov na okolje.

- $\quad$ Direktiva 2004/35/ES Evropskega parlamenta in Sveta z dne 21. aprila 2004 o okoljski odgovornosti v zvezi s preprečevanjem in sanacijo okoljske škode.

- Direktiva 2004/101/ES Evropskega parlamenta in Sveta z dne 27. oktobra 2004 o dopolnitvi Direktive 2003/87/ES o vzpostavitvi sheme za trgovanje s pravicami za izpuščanje toplogrednih plinov $\vee$ Skupnosti, upoštevajoč projektne mehanizme Kjotskega protokola.

- Directive 2006/11/ec of the European parliament and of the Council of 15 February 2006 on pollution caused by certain dangerous substances discharged into the aquatic environment of the Community. 
SUMMARY

\section{CHANGING PROCESS OF ENVIRONMENT PROTECTION ACT (EPA) - IN WHICH WAY?}

According to the Slovenian Constitution everyone has the right to a healthy living environment. Moreover, the state should make effort to promote it. With this purpose the conditions and manner in which economic and other activities are pursued is enacted by the law. The law defines under which conditions and to what extent a person who has damaged the living environment is obliged to provide compensation.

Environment Protection Act (EPA) is the most important act in Slovenia, which regulates the protection of the environment in our country. EPA defines instruments for establishing basic conditions for sustainable development, and within this framework lays down basic environmental protection principles, (environmental protection) measures, (environmental) monitoring and (environmental information) as well as, economic and financial instruments for environmental protection, public services for environmental protection and other related issues.

The most important basic principles are:

- The principle of prevention specifying that emission limit values, environmental quality standards, rules of conduct and other environmental protection measures shall be designed and each activity affecting the environment shall be planned and carried out in such way that it causes minimal environmental burden.

- The precautionary principle, specifying that introduction of new technologies, production processes and products shall only be permissible when no unforeseeable detrimental effects on the environment or human health could be expected.

- The "payment for burden" principle, specifying that the person responsible for the burden shall cover all the costs of prescribed measures for the prevention and reduction of pollution, environmental risk, use of the environment, and elimination of the consequences of environmental burden.

- The principle of admissibility of activities affecting the environment, specifying that an activity affecting the environment shall only be admissible if it does not cause an excessive burden. EPA specifies the cases where an environmental protection consent or 
Adrijana Viler Kovačič

Spremembe zakona o varstvu okolja - v kateri smeri?

permit shall be required for an activity affecting the environment. EPA specifies the cases where an environmental protection consent or permit shall be required for an activity affecting the environment.

EPA was adopted in 2004. Nowadays, there are several reasons that demand an amendment of this act.

The first one is the implementation of the Directive of the European Parliament and of the Council of 21 April 2004 on environmental liability with regard to the prevention and remedy of environmental damage into the Slovenian law. This directive entered into force on 30 April 2004, but EU Member States have had three years to implement the Directive into the national law. The Directive 2004/35/EC was adopted after the realisation that there are currently many contaminated sites in the Community, posing significant health risks, and that the loss of biodiversity has dramatically increased over the last decades. Failure to act upon could result in an increased site contamination and greater loss of biodiversity in the future. Preventing and remedying environmental damage, insofar as is possible, contributes to the implementation of objectives and principles of the Community's environmental policy as set out in the Treaty. Local conditions should be taken into account when deciding how to remedy the damage. The Directive defines and establishes the rule according to the "polluter-pays" principle, stating that an operator causing environmental damage or posing an imminent threat of such damage should, in principle, bear the costs of necessary preventive or remedial measures. In cases where a competent authority acts itself or through a third party on behalf of the operator, that authority should ensure that the costs incurred are recovered from the operator. It is also appropriate that the operators ultimately bear the costs of assessing environmental damage and, as the case may be, assessing an imminent threat of occurance of such damage. This Directive aims at preventing and remedying environmental damage and does not affect rights of compensation for traditional damage granted under any relevant international agreement regulating civil liability. Slovenia has not implemented this directive yet, but it will have done so since the time has run out.

The second reason that forces Slovenia to amend EPA is to eliminate the current problems in the EU Emission Trading Scheme. According to the Directive 2004/101/EC of the European Parliament and of the Council 
of 27 October 2004 amending the Directive 2003/87/EC establishing a scheme for greenhouse gas emission allowance trading within the Community, in respect of the Kyoto Protocol's project mechanisms, Slovenia must, as all other European countries in EU, facilitate in the most costeffective manner joint investments in projects on environmental burden reduction (hereinafter (referred to as) "joint investment") with a view to reduce the burden on the environment by greenhouse gas emissions. Joint investment shall be of a legal or natural person under domestic law and a foreign natural or legal person having residence or registered office outside the territory of the Republic of Slovenia. Joint investment shall comprise of the investment of capital into development and use of technologies that eliminate or reduce pollution or use of the environment, and of their transfer. The amendments of the EPA must provide the verification process more consistent and more comparable to the legislations/verification processes of other EU Members States especially if Slovenia decides to host project activities.

In these four years, in which EPA is in force, we have gained a lot of experience in environmental impact assessment. According to EPA, environmental impact assessment shall be carried out on the basis of the report on environmental impacts of planned activity (hereinafter (referred to as) "the environmental impact report"). The report maker can be anyone. The entity responsible for the planned activity must provide for a revision of the environmental impact report. A revision of the environmental impact report should present an independent expert control over the quality and suitability of environmental impact report. These reports in fact did not bring more quality in environmental impact reports, which was the purpose of revisions. Analysis showed that revisions represent more or less only costs for the applicant. A better solution would be to abolish this expert control and provide that no one but the persons, who have obtained a licence to do reports, do the reports.

In the procedure for environmental impact assessment the ministry must make the application for environmental protection consent and other concerning documents available to the public. A person permanently residing in the area or owning or possessing a real estate, has a legitimate interest in line with the regulations on administrative procedure and has the status of an accessory participant in the procedure. The status of accessory participant in the procedure for granting the environmental protection consent is enjoyed by a non-governmental organisation. It is 
Adrijana Viler Kovačič

Spremembe zakona o varstvu okolja - v kateri smeri?

evident that EPA is not clear enough about the question who can be involved and what is the appropriate time to enter this process. This problem has caused a lot of different opinions by different decision makers.

Environmental protection permit is a permit that the operator must obtain for the operation of:

- Installations where an activity might cause large-scale environmental pollution;

- any other installation that is not specified above, if an activity is pursued in that installation that causes emissions into air, water or soil for which limit values are prescribed or if it treats or disposes of waste,

- a plant posing a risk.

When the operation of installation or a substantial change in its operation requires construction, the operator must obtain the environmental protection permit prior to the start of such construction, and in other cases prior to putting it into operation.

The requirement of these permits is ordered by many directives, except environmental protection permit for the operation of a plant posing a risk. In this case the Directive 96/82/EC, which regulates the rules for persons who operate a plant posing a risk, does not demand to have a special permit. The question is whether this permit is necessary and whether EPA can replace the obligatory permits according to the Directive with other instruments (i.e. better inspections). The latter would be an approximation of Lisbon strategy because the procedure of issuing permits by the competent body is very long and expensive. The next question is whether it is necessary to obtain the environmental protection permit for any other installation that is not specified above, where an activity takes place causing emissions of air, water or soil pollutants falling under the prescribed limit values or treatment or disposal of waste activities or disposes of waste, prior to the start of construction, that means before obtaining a construction permit. This situation means a delay for the operator to start building a construction and for the competent body to issue a permit with hypothetical data. The regulation when the environmental protection permit is not mandatory before the start of the construction is not against the directives. If we change the time of obtaining this permit to after having built a construction and before operating the installation, it could be much easier for the operator to start building and for the competent body to issue a permit as well. 